\title{
Crowd Arbitration: Blockchain Dispute Resolution
}

\section{目 Aleksei Gudkov}

Associate Professor, Department of Theory of Law and Interdisciplinary Studies, National Research University Higher School of Economics, PhD. Address: 20 Myasnitskaya Str., Moscow 101000, Russia. E-mail: ag2868@gmail.com

\section{昰目 Abstract}

Internet technology makes digital value transactions between anonymous individuals possible, but leaves unanswered the question of how to resolve disputes between unidentified parties. Blockchain dispute resolution platforms provide a response to this problem. In the social dispute resolution systems for blockchain currently in use, pseudo anonymous jurors can resolve disputes between pseudo anonymous parties. This paper presents Kleros as the most illustrative blockchain dispute resolution platform BDRP. To describe the features of the Kleros dispute resolution platform and the qualification of jurors, this research employs an online dispute resolution survey of both the jurors and stakeholders of the Kleros platform. This study raises important questions about key elements of procedural justice in resolution platforms for blockchain disputes. The research underlines the pros and cons of dispute resolution for crowdsourced blockchain and contributes to the further development of online dispute resolution systems. It tests the wisdom of the crowd as the core attribute of the resolution process in crowdsource disputes. Crowdsource mass dispute resolution, coupled with cooperative jurors and blockchain technology, could ensure greater effectiveness and fairness of the dispute resolution process, especially the adjudication of online small claims disputes.

\section{O-1国 Keywords}

blockchain; dispute resolution; distributed arbitration; social justice; blockchain court; online justice; ODR, crowd arbitration.

For citation: Gudkov A.V. (2020) Crowd Arbitration: Blockchain Dispute Resolution // Legal Issues in the Digital Age, no 3, pp. 59-77.

DOI: $10.17323 / 2713-2749.2020 .3 .59 .77$

\section{Introduction}

Online technologies are part of everyday life. Online interactions, including online commerce, freelance activities, values exchange, transactions with cryptoassets, and the network infrastructure to support these activities are growing. The number of cross-border small trade transactions conducted online has sig- 
nificantly increased as well. For example, the total number of cross-border buyers on AliExpress grew from 10 million in 2014 to 150 million in $2018^{1}$. Inevitably, this has triggered an increase in the number of disputes, including a clear upward trend in the number of small, cross-border disputes.

The development of blockchain technology has made it possible for anonymous persons to carry out decentralized payment settlements and has made it even more difficult to resolve disputes between persons acting online. There are social and legal ramifications, caused by market demands that change the approaches relating to the dispute resolution process. Online commerce requires that disputes be settled quickly, securely and fairly, and that they be enforceable despite problems with identification and distance. Technological progress provides an opportunity to improve the dispute resolution process. Blockchain technology is well-suited to these needs. Blockchain dispute resolution is a crowdsourced online dispute resolution system that uses blockchain technology to set up arbitration, organize dispute adjudication, and reward jurors.

This study examines the technological, social and legal solutions for dispute resolution, focusing on the adaptation of blockchain technology to the international justice system. It introduces the existing models of dispute resolution and primarily weighs the advantages and disadvantages of blockchain dispute resolution for online platforms. It also examines the application of blockchain technology in disputes between unidentified persons; the effects of the wisdom of the crowd when considering fairness; and the characteristics of procedural justice in blockchain dispute resolution.

This study is based on an online dispute resolution practice and data analysis, obtained from a survey (hereafter, the Survey) of the jurors and stakeholders of the Kleros blockchain dispute resolution platform. The Survey contains twenty questions to evaluate the skills and preferences of Kleros jurors and stakeholders. The study also assesses the characteristics of the adjudication process on blockchain platforms.

\section{Dispute Resolution Models}

There are three general models of dispute resolution: state court litigation; professional arbitration, including religious tribunals; and crowdsource dispute resolution, including blockchain dispute resolution. A modern technological solution also exists: automated conflict resolution systems such as an artificial intelligence judge. Every dispute resolution model has certain advantages and disadvantages.

${ }^{1}$ CIW. 2018. Alibaba's cross border e-commerce platform AliExpress reached 150 million buyers. Available at: https://www.chinainternetwatch.com/26756/aliexpress-social-ecommerce/ (accessed: 18.08.2019) 


\subsection{State Court}

State courts take a professional approach to the dispute resolution process. The main advantage of the state court is that its judgments can be enforced by a coercive state power. However, because state courts have long, drawn out and costly procedures for dispute resolution, litigants in online trading disputes usually do not file lawsuits to a state court. Even specially created small claims state courts cannot fully meet the needs of disputing parties. For example, in Japan, a Small Claims trial takes approximately two months, from the filing of the case to the final judgment. The cost to file such a case is almost half of the value of an average e-commerce purchase [Habuka H., 2017: 79].

\subsection{Professional Private Arbitration}

For many centuries, professional arbitration has been the only option for dispute resolution. Its roots date back to early Greek, Roman and Jewish communities [Barrett J., 2004: 2-19]. The main advantages of arbitrators are speed and fairness: professional arbitrators resolve disputes faster than state courts do and the knowledge and reputation of individual arbitrators guarantee fairness.

The growth of online commerce caused an increase of small disputes between geographically distant parties. Small online disputes necessitate a rapid and costeffective resolution process. As a result, online dispute resolution (hereinafter ODR") was developed.

\subsection{Online Dispute Resolution}

In response to market needs, some states help private arbitrators to organise online dispute resolution platforms. Online dispute resolution is a settlement carried out by combining the information processing powers of computers with the networked communication facilities of the Internet [Hörnle J., 2009: 75]. ODR is a form of dispute resolution in which reputable arbitrators adjudicate claims online. For example, the European Online Dispute Resolution platform, organized by the European Commission, provides access to dispute resolution tools. Private, authorized dispute resolution bodies offer out-of-court settlement procedures through this platform. The European Online Dispute Resolution platform resolved more than 36,000 cases in $2018^{2}$.

2 European Commission. 2018. Functioning of the European ODR Platform. Available at: https://ec.europa.eu/info/sites/info/files/2nd_report_on_the_functioning_of_the_odr_platform_3.pdf, (accessed: 03.08.2019) 


\subsection{Crowdsourced Dispute Resolution}

Crowdsourced dispute resolution is an offline or online form of extrajudicial tribunal. Whereas offline mob justice can descend into criminal actions such as a lynching, the needs of the online market shift the focus to online dispute resolution. Crowdsource dispute resolution is a common solution for groups seeking to manage themselves by creating rules and establishing authorities and institutions to facilitate social regulation [Tyler T., 2000: 118-119].

In contrast to competent court judges and professional arbitrators, crowdsource arbitration consists of untrained jurors demonstrating jointly the wisdom of the crowd.

Commercial online platforms incorporate a number of systems for crowd dispute resolution. The ODR systems at eBay and PayPal process 60 million cases per year, 90 percent of which are resolved through automation. Another online dispute resolution platform, Modria, has handled more than one million cases in the United States and around the world ${ }^{3}$.

\section{Online Blockchain Dispute Resolution}

Blockchain technology introduces a novel element in online dispute resolution. Never before have disputes between pseudonymous persons been resolved by pseudonymous jurors with a lower risk of manipulation. Blockchain dispute resolution is a type of online dispute resolution. Because blockchain technology helps to manage data, preserve evidence and keep procedures fair, it has the potential to improve traditional proceedings. There are two types of blockchain dispute resolution, depending on the professional skills and number of jurors involved. The first employs professional arbitrators, while the second relies on a crowdsourced model of dispute resolution.

Dispute resolution can be carried out as a main activity or as an additional service.

Kleros and Rhubarb are the most well-known platforms specializing in blockchain dispute resolution. They employ blockchain technology and crowdsource methods to adjudicate disputes fairly and in a decentralized manner. Both Rhubarb and Kleros base their platforms on the ancient Greeks' approach to disputes that offers a reward to the person whose suggested resolution succeeds in bringing the parties to an agreement. Kleros provides advanced technical solutions and services, such as smart contracts and escrow. Kleros uses blockchain technology

${ }^{3}$ Modria. Online Dispute Resolution, p.6. Available at: https://www.tylertech.com/Portals/0/OpenContent/Files/4080/Modria-Brochure.pdf (accessed: 26.09.2019) 
to maintain network security, register jurors, organize reward distribution among jurors, and enforce the jury's decision.

Dispute resolution, as an additional service, is carried out by the Baidu and Alibaba-Taobao platforms. In addition to being a search engine, communication and technological service, Baidu has its own online judicial arbitration system. The Baidu blockchain judicial arbitration system was built on blockchain in collaboration with the Qingdao Arbitration Commission to solve the problem of online trials and realtime electronic evidence preservation. The online trading platform Alibaba-Taobao uses public assessors to resolve e-commerce disputes arising on the platform. Alibaba-Taobao arbitration systems, like Baidu, use the immutability of blockchain to construct a trustworthy register of evidence from original sources.

\section{The Advantages of Blockchain Dispute Resolution}

\subsection{Judgments of Unidentified Persons}

It is impossible to identify individual blockchain users. They leave only indirect identifying signs such as a crypto address, pseudonym on a social network, email address or IP address. In traditional court proceedings, it is necessary to disclose a person's identity. However, to resolve a small dispute quickly, many online dispute resolution platforms do not require personal identification. In this case, blockchain dispute resolution provides a means for working with anonymous users, making it possible to conduct operations and settle disputes without confirming the identity of either party. It is now possible for dispute resolution systems based on blockchain technology to have unidentified jurors resolve conflicts between unidentified parties. The main idea behind dispute resolution on blockchain is that a number of anonymous jurors, who do not have to trust each other, can reach consensus on a just decision ${ }^{4}$. The main advantage of blockchain dispute resolution is that unidentified judges can openly express their opinion of what is fair with regard to the actions, rights and obligations of nameless persons.

\subsection{Reputation Built on Historical Data}

Blockchain technology assumes pseudonymity and a lack of identity. Cooperation on blockchain platforms is controversial. It is difficult to trust and cooperate with an unknown person. Axelrod [Axelrod R., 1981: 6] believes that the foundation of cooperation is not really trust, but the durability of the relationship. This

${ }_{4}^{4}$ Ast F., Bergolla L. et al. Dispute revolution. The Kleros handbook of decentralized justice. Available at: https://ipfs.kleros.io/ipfs/QmZeV32S2VoyUnqJsRRCh75F1fP2AeomVq2Ury2fTt9V4z/Dispute-Resolution-Kleros.pdf (accessed: 14.08.2019) 
quality of durability is only achieved by observing the full history of transactions by crypto-accounts on a blockchain network. Blockchain technology can guarantee the immutability of crypto-account historical data and assure, with cryptographic proof, that the data is real. Therefore, trust in blockchain dispute resolution and the soundness of its reputation could be grounded on the fact that all of a crypto-account's historical data is transparent and easily inspected. The existence and intentions of the parties are verified by the fact of a dispute, the evidence provided, the fee for the case proceeding, and historical data of the account from which the cryptoassets were transferred. The transparency and immutability of blockchain network data can substitute for the traditional approach to reputation that is based on opinion and word of mouth.

\subsection{Immutability of Execution}

Dispute resolution platforms do not possess coercive power by themselves. In a traditional dispute resolution process, the responsible bodies enforce the award reached through arbitration. However, the verdict of the jury in blockchain dispute resolution can be executed via smart contract without the need for enforcement by a state court. This holds particularly true for cryptocurrencies and other cryptoassets. Because a smart contract is based on blockchain technology, the execution of the arbitrator's award is automatic. This self-enforcement, agreed to by the disputing parties and made possible through modern technology, ensures its execution. The Kleros platform has a smart contract that locks the disputed cryptoassets into escrow and transfers them to the winning party upon adjudication. This process is irreversible. Thus, in many cases, a blockchain dispute resolution could be viewed as the final decision. This is especially true for anonymous parties.

The immutability of a cryptoassets award based on a decision by anonymous online jurors does not abrogate the right to seek protection in a state court, although, in many countries, an arbitration award is final in the sense that awards have res judicata effect. To be precise, once an award has been made, and unless the award is successfully challenged, the same matter cannot be brought before a court or arbitration tribunal again [Hörnle J., 2009: 101].

\subsection{Cooperative Crowdsourcing}

In ancient times, one way to settle conflicts was to enable a crowd to make a judgement. Crowdsource dispute resolution is the practice of replacing judges, arbitrators or mediators with a group of people called the crowd"5. The primary purpose

${ }^{5}$ Dimov D. Crowdsourced online dispute resolution. Available at: https://openaccess. leidenuniv.nl/bitstream/handle/1887/50156/Crowdsourced_Online_Dispute_Resolution_3e. pdf? sequence=1 (accessed: 23.09.2019) 
of most BDRPs is to organize members of the blockchain community for participation in dispute resolution as jurors. The capability to exchange individual opinions and the possibility to vote by means of blockchain technology make it possible to produce a single collective judgment. The crowdsourced ODR mechanism assists the parties in their negotiations for a settlement by reality-testing their positions against the supposed common sense of the volunteers forming 'the jury' [Hörnle J., 2009: 82].

Crowdsource dispute resolution has become more accessible with the growth of Internet technology. The online crowdsource dispute resolution platform is able to handle a substantially larger number of disputes than conventional arbitration. For instance, from 2012 to 2014, the Taobao User Dispute Resolution Center settled an average of more than 2,000 consumer grievances per day, including 238,000 online-shopping disputes in 2013 alone ${ }^{6}$.

\subsection{The Wisdom of the Crowd}

Crowdsource dispute resolution exploits the wisdom of the crowd principle. According to this concept, all members of a society are holders of the fairness existing within that society. The more members of the society that are included in a certain community, the more power that community has to resolve disputes. The wisdom of the crowd utilizes fairness from bottom to top, as compared to the traditional model of justice in which a limited group of professionals interprets laws and hands doctrinal rulings down from top to bottom.

From a psychological standpoint, crowdsource dispute resolution is a crowdbased socio-cognitive system composed of groups of independently thinking individuals [Surowiecki J., 2004: 42]. The system is based on the idea that a diverse group of autonomous agents, each with different models, perceptions, motivations and rationality, can often analyze or predict scenarios or data more effectively than individuals can, even when those individuals are specialists in their area of expertise ${ }^{7}$.

The jurors use a process of metacognition to improve joint action. Metacognition allows the jurors to monitor their own thought processes, taking into account the knowledge and intentions of others [Boddington P., 2017: 81]. A single juror operating alone cannot apply this approach: to enhance fairness, jurors must cooperate and share their thoughts.

${ }^{6}$ Erickson J., Wang S. How Taobao Is Crowdsourcing Justice in Online Shopping Disputes. Available at: https://www.alizila.com/how-taobao-is-crowdsourcing-justice-in-online-shopping-disputes/ (accessed: 14.08.2019)

7 Noriega P. Crowd-based socio-cognitive systems. Crowd Intelligence: Foundations, Methods and Practices. Available at: http://research.gold.ac.uk/id/eprint/10370/ (accessed: 27.08.2019) 
In terms of procedural justice, platforms for blockchain dispute resolution employ a group engagement model with discretionary cooperation. That is, it taps into the internal motivation of each member, as compared to mandatory cooperation that is stipulated by a group [Tyler T., 2003: 353]. However, the discretionary cooperation between Kleros jurors and members differ. As a rule, jurors on Kleros and other platforms are willing to cooperate. The Survey shows that more than 76 percent of jurors on Kleros are willing to discuss details of a case with other jurors and members. However, in contrast to jurors, 57 percent of the members of a community are not ready to discuss a case with jurors. Therefore, Kleros community members are less cooperative than jurors are.

The crowd can provide unexpected solution capacity and find a solution faster than individual experts can. According to Rader, when the Roche company had a problem with the precise measurement of sample quality and quantity, it offered a prize and a viable solution was found within six weeks. Moreover, it turned out that the non-winning submissions replicated everything that Roche had tried over its 15 years of proprietary research. The curated crowd of people was able to solve difficult technical problems with a 92 percent success rate, save an average of 60 percent in cost over traditional methods, and solve most problems twice as fast as traditional methods ${ }^{8}$. Crowdsourcing achieves this by dividing a large job that might be too difficult or time-consuming for one person into smaller actions that many people work to solve [Kolb B., 2013: 173].

Crowdsource dispute resolution can resolve a larger number of disputes than professional arbitration. For example, China's Taobao online marketplace employed a crowdsourced resolution process that utilizes online juries to resolve millions of disputes between 2014 and 2017 [Habuka H., 2017: 76]. Thus, crowdsource dispute resolution using cooperative jurors achieves greater effectiveness and fairness than other methods.

\subsection{Jurors}

Blockchain technology allows the development of a jurors' forum of unlimited size. According to [Dimov D., 2017: 25] crowdsourcing applications are ineffective if too few people participate. But what is the minimum number of jurors required to demonstrate fairness? In simple cases where most members of a population would choose a single solution, a jury of three to five members could accurately represent the opinion of the entire population In a complicated case, the more jurors who par-

${ }^{8}$ Rader S. The Power of Crowd Based Challenges NASA's Practical Toolkit for Open Innovation. Available at: https://ntrs.nasa.gov/archive/nasa/casi.ntrs.nasa.gov/20170012345.pdf (accessed: 24.08.2019) 
ticipate in the arbitration, the fairer the judgment is. Public participation programs are more successful if more people participate [Lawrence R., 1997: 21].

The Taobao User Dispute Resolution Center attracted more than 575,000 jurors between 2012 and 2014. The jurors sat on 31-member panels that reviewed evidence submitted by feuding buyers and sellers. Volunteer jurors can choose cases according to their interests and may participate in up to 20 cases per day ${ }^{9}$.

The Kleros platform declared that the resolution of disputes would be achieved through crowdsourcing [Ast F., 2019: 41-42]. In 2019, most juries had few members and even the pool of potential jurors was limited in size. As a rule, first-round juries were composed of from three to five members. The parties determine the exact number of jurors. Kleros has the potential to attract more jurors and operate as a strong crowdsource platform.

According to the Survey, 46 percent of Kleros jurors believe that they can resolve from two to five cases per day. The difference between Taobao and Kleros is reflected in the complexity of the cases they address. As a rule, Kleros disputes are more challenging.

Kleros jurors tend to have solid common sense, strong logic and a good grasp of blockchain technology. According to the Survey of Kleros community members and jurors, 86 percent of jurors and 71 percent of members successfully resolved complex logical tasks; 86 percent of jurors and 57 percent of members correctly understood the meaning of basic legal terms; and 54 percent of jurors and 28 percent of members were able to resolve professional legal cases. Therefore, Kleros jurors have the potential to resolve not only simple conflicts, but also disputes with a medium level of complexity, especially in the blockchain industry.

Thus, the fairness of the crowd-based socio-cognitive dispute resolution process, among others, depends on the number and qualification of jurors taking part in the adjudication process. Small claims can be effectively resolved online.

\subsection{Technological Advantages}

Online Blockchain dispute resolution is carried out in electronic form. All communication, notifications, documents and evidence, are made digitally. This technology reduces costs and increases speed. The blockchain technology itself ensures that data are secure, immutable and transparent and all operations are carried out on a distributed ledger. Specifically, blockchain technology is used to transfer payments among participants, including rewards for the jurors, and to register jurors and count jurors' votes during the adjudication process.

9 Available at: https://www.alizila.com/how-taobao-is-crowdsourcing-justice-in-onlineshopping-disputes/ (accessed: 14.08.2019) 
The most well-known application of blockchain technology is smart contracts that ensure the conditional transfer of values among disputing parties and the court. Agreements incorporated into the smart contract or the execution of the smart contract can be appealed to a dispute resolution platform or national court.

Thus, technology ensures access to the dispute resolution process and justice.

\subsection{Wide Audience}

The potential audience of a BDRP is not restricted to a certain class of users or nations. The ODR on blockchain is not dedicated only to blockchain users. Standard online and e-commerce disputes could utilize it, too. Blockchain dispute resolution is based on a common understanding of justice and an agreement of a compact society (members of the dispute resolution platform) on the fairness and principles of justice. The society is a more or less self-sufficient association of persons who, in their relation to one another, recognize certain rules of conduct as binding and who, for the most part, act in accordance with them [Rawls J., 2009: 4]. In this sense, a BDRP focuses primarily on the persons associated with such a distributed stateless society. The jury can make judgments and interact across national borders. Everyone who accepts the dispute resolution principles of the platform can take part as a juror or disputing party. The independence of jurors and shared values make blockchain dispute resolution advantageous for many cases all over the world.

\subsection{Pluralism of Opinions}

Blockchain dispute resolution jurors hail from many different countries and cultures and their varying approaches to fairness are rooted in differing religions, traditions and beliefs.

This technology makes it possible for everyone to act as a juror regardless of his or her nationality, ethnicity, religious persuasion or age. The diversity of jurors' opinions facilitates fairness and prevents vigilante justice.

\subsection{Higher Speed and Lower Cost}

National court proceedings and traditional dispute resolution are slow owing to the need to examine evidence thoroughly and also due to bureaucracy.

The significant time and money required to resolve disputes in state courts are the reasons why many have switched to online arbitration. From a purely utilitarian point of view, it makes no sense for the claimant to apply to a foreign court to resolve cross-border small claims and spend a lot of time and money on compli- 
cated procedures. Cross-border litigation and enforcement are very expensive and time-consuming, and in the case of small claims, the costs and delays involved are frequently disproportionate to the eventual remedy [Hörnle J., 2009: 44].

Blockchain dispute resolution processes information faster than an individual arbitrator can. The opinion poll model allows parties to express their opinions about a dispute without using legal language, revealing their names or taking a fee ${ }^{10}$.

Crowd-sourcing is cost effective. For example, volunteers in the Taobao User Dispute Resolution Center resolved disputes without reward ${ }^{11}$. Jurors on the Rhubarb dispute resolution platform cover their own expenses, charging nothing to the disputing parties for rendering a decision ${ }^{12}$. Rader estimates that in-house development is anywhere from three to 10 times more expensive than crowd-based development ${ }^{13}$.

Therefore, online dispute resolution generally and the crowdsource model in particular are fast and cost-effective methods for resolving disputes.

\section{Drawbacks of Blockchain Dispute Resolution}

\subsection{Aggregate Decisions Can be Unfair}

Not every crowd is efficient. There is a difference between jurors making collective versus aggregate decisions. The collective decision assumes an exchange of opinions to influence the judgment of others. According to [Tideman N., 2017: 5], a collective decision occurs when members of a group make individual decisions that they would not make if the other members were not also making related decisions. A collective decision thus entails a coordination of intentions. If, however, the other members do not influence individuals of the group or crowd, they make what is called an aggregation of decisions ${ }^{14}$. The crowdsourced model of dispute resolution does not work when jurors reach decisions separately. There is no wisdom of the crowd in an aggregate decision. Thus, an aggregate decision is not as fair as a cooperative decision, although this is not so critical in a simple dispute.

${ }^{10}$ Martic D. Blind Arbitration Proposal for Anonymous Crowdsourced Online Arbitration. Sintelnet WG5 Workshop on Crowd Intelligence: Foundations, Methods and Practices. 2019. European Network for Social Intelligence, pp. 94-107.

11 Available at: https:/www.alizila.com/how-taobao-is-crowdsourcing-justice-in-onlineshopping-disputes/ (accessed: 14.08.2019)

12 Rhubarb. FAQ. Available at: https://www.rhucoin.com/faq.aspx (accessed: 26.08.2019)

13 Available at: https://ntrs.nasa.gov/archive/nasa/casi.ntrs.nasa.gov/20160012792.pdf (accessed: 24.08.2019)

${ }^{14}$ Dimov D. Crowdsourced online dispute resolution. Available at: https://openaccess. leidenuniv.nl/bitstream/handle/1887/50156/Crowdsourced_Online_Dispute_Resolution_3e. pdf? sequence=1 (accessed: 23.09.2019) 
An aggregate decision can be fair due to the existence of a so-called focal point. The focal point is the expectation of a conclusion that people whose actions are not coordinated tend to have in the absence of communication. Most situations provide some clue for coordinating behavior, some focal point for each person's expectation of what the other expects him to expect to be expected [Schelling T., 1980: 57]. Thus, jurors can find a common solution without any communication or coordination. The focal point depends on people's level of rationality, which is based on precedent or common knowledge [Sugden R., 1995: 544]. In the international community, however, cultural rationality can be diverse. The focal point can shift even under unintentional contact. The focal points may certainly be different when speech is allowed [Schelling T., 1980: 73].

In practice, many ODR platforms use an aggregate decision model. In a blockchain society, reputation carries less importance due to the anonymous nature of the technology. Most of the judgments on the Kleros platform are aggregate. The jurors have no obligation to discuss the evidence.

There are no formal procedures for jurors' meetings. In terms of procedural fairness, giving people fair procedures means putting more emphasis upon informal dispute resolution [Tyler T., 2000: 121]. Therefore, informal Kleros procedures facilitate fairness.

To prevent manipulation of the result, Kleros prevents jurors from disclosing their votes before the result is made public. The efficacy of the crowd-based solution is dependent on the precision of the information signal received by each agent, which varies with agent sophistication and task complexity [Ma P., 2016: 26].

At the same time, the Survey shows that 85 percent of Kleros jurors are willing to discuss case details with members of the larger Kleros community, and as many as 77 percent of the jurors are willing to discuss the case with other jurors.

Jurors on the Rhubarb platform can discuss and debate the merits of the proposal under consideration until the final vote is due. They can also ask questions or try to convince the disputants to agree to the terms for which they intend to vote ${ }^{15}$.

Although the exchange of opinions generally slows the adjudication process, it should be obligatory for the resolution of complicated cases. Otherwise, it would not draw on the wisdom of the crowd and could produce a decision that is less fair.

\subsection{Manipulations and Collusions}

In traditional methods of dispute resolution, it is essential that the disputing parties trust in the neutrality of the jurors.

${ }^{15}$ Rhubarb. FAQ. Available at: https://www.rhucoin.com/faq.aspx (accessed: 26.08.2019) 
By contrast, any blockchain transaction can be concluded successfully without need of mutual trust because the technology effectively secures transactions involving cryptoassets between unidentified persons. Trust in jurors also plays no role because their identities remain unknown both to the disputing parties and, if desired, to each other. For example, jurors on the Rhubarb platform must disclose their names and email addresses, and provide proof of U.S. citizenship. However, Rhubarb does not validate this information. Thus, the anonymous nature of the users, the fact that one person can generate multiple accounts and the complete absence of personal reputation means that manipulation and collusion could be widespread on blockchain dispute resolution platforms. One person could create multiple pseudonymous accounts and act under the guise of several jurors to gain a disproportionately large influence. This is known as a Sybil attack, where a node illegitimately claims multiple identities ${ }^{16}$. The lack of a mechanism for validating identities makes it impossible to prevent various biases and manipulations such as secret agreements or alliances. This creates additional risk for the parties. Relying on jurors with proven reputations mitigates such risk. The anonymity of the members of the crowd participating in online opinion polls decreases their transparency. This, in turn, can have a negative influence on both objective and subjective procedural fairness [Dimov D., 2017: 169]. In the absence of a mechanism for establishing a reputation, blockchain dispute resolution could tend towards becoming less fair.

If jurors follow strong moral guidelines, it can prevent manipulation of the dispute resolution process. In practice, cooperation purely with the motive of achieving a fair dispute resolution could substitute for cooperation based on self-interest or remuneration. The Kleros and other blockchain-based dispute resolution platforms were created to render arbitration as a commercial service. The main motivation of Kleros jurors is to earn money, as compared to the volunteer jurors of the Taobao online retailer, who resolve disputes without reward. Self-interest and egoistic cooperation impair justice. Any manipulation or collusion in the adjudication process is fraud and prevents jurors from treating the parties in a dispute with neutrality and impartiality. By definition, a decision is fair when all parties are treated equally [Hörnle J., 2009: 15-18].

Unbiased, neutral jurors [Mansbridge J., 1990: 176] should make the decisions in dispute resolution. Kleros has successfully introduced a number of procedures, such as appellation and jurors making cryptoasset deposits that make it more difficult and costly to manipulate the process. Kleros also allows participants to ap-

${ }^{16}$ Newsome J., Elaine S., Dawn S., Adrian P. The sybil attack in sensor networks: analysis \& defenses. In: Third international symposium on information processing in sensor networks. 2004. pp. 259-268. 
peal decisions to a new jury. The essence of appellation is that every appeal doubles the number of jurors. It might be possible to bribe two or three jurors in an initial round, but it is difficult to use subornation for the larger number of jurors involved in subsequent appeals. Additionally, disclosing jurors' identities and establishing their reputations could serve as a deterrent to coordinated manipulative practices. Collusion remains a serious challenge for Blockchain dispute resolution platforms. One of the parties could coordinate with or control the jurors to obtain an advantageous ruling. For a system of justice to be effective, behavior must be shaped by judgments about what is right, regardless of personal interests or gain [Tyler T., 2000: 118].

\subsection{Incorrect Judgments Stemming from Herding Behavior}

When jurors have little information on a subject, they rely on the judgments of others, resulting in so-called herding behavior or informational cascade. This can be defined broadly as the alignment of the thoughts or behaviors of individuals in a group (herd) through local interaction and without centralized coordination [Raafat R., 2009: 424]. The jurors reach consensus not by a process ofthorough deliberation, but by obeying or aligning themselves with the opinions of others. The process of jury deliberation may engender consensus, but at the cost of potentially amplifying the errors of some jurors, thereby leading to incorrect judgments [Luppi B., 2013: 24]. The main problem is that herding behavior has the potential to violate a disputant's human rights and could lead to rule by so-called mob law."

\subsection{Lack of Control Over the Process}

Technology can prove a substantial barrier for users, particularly when they have doubts about their ability to operate on a given platform and whether they can obtain the necessary assistance in time [Lu Z., 2017: 364]. Furthermore, disputing parties who apply for arbitration seek intervention by jurors, but not necessarily an imperative ruling that they must blindly obey.

Disputants desire some third-party control in dispute-resolution procedures, but they generally reject any type of autocratic control [Lind A., 1988: 15]. Although major or complicated cases demand more time and less stringent controls, disputants with time constraints who pursue common goals and who agree on a standard that can be applied quickly to resolve differences in belief might agree to more autocratic adjudication [Thibaut J., 1975: 552-554]. Thus, faster and more autocratic solutions are more suitable for small cases.

Due to the peculiarities of blockchain technology, a jury decision in blockchain dispute resolution cannot be changed once it is executed. The automatic execution 
built into a smart contract might not reflect the desire of the disputants. And because all blockchain actions are recorded on a distributed ledger, such judgments are, ultimately, irreversible. As a result, parties can essentially lose control over a dispute when they utilize blockchain technology.

\subsection{Common Sense Instead of Applicable Law}

Alternative forms of dispute resolution, especially international online blockchain dispute resolution, generally have little in common with national laws. In the case of e-disputes, and especially cross-border e-disputes, it is not always obvious which laws apply ${ }^{17}$. The blockchain stateless society tends towards an anarchical vision of fairness. Jurors appeal directly to natural human rights and morality, skipping intermediary national law. In most cases, jurors on a blockchain platform rely more on common sense and logic than they do the laws of this or that country.

According to the Survey, 84 percent of Kleros jurors believe that they should not have to determine a national jurisdiction to which the dispute is most closely connected.

In simple disputes with clear solutions, jurors have wide discretion in applying adjudication standards. However, this approach would be unfair and unacceptable for major or complicated cases. Even when the parties to a dispute choose substantive and procedural law, or lex arbitr rules in their agreement to arbitrate, jurors could not apply such laws if they had no specific knowledge of them. Interestingly, the inability to apply a certain law does not necessarily discourage jurors in online adjudication. According to the Survey, even if the parties were to choose the law of Afghanistan for their arbitration case - that is unfamiliar to the vast majority of potential jurors -61 percent of Kleros jurors were willing to take part in dispute resolution anyway.

\subsection{Low-Skilled Jurors}

When jurors are highly qualified, their decisions are naturally fair. However, it is necessary to differentiate between someone with a narrow specialization in, for example, blockchain technology, and a broadly qualified judge who has specialized knowledge in logic, justice, forensics and law. Thus, unlike judges in a national court, online jurors often do not possess professional arbitration skills and so their decisions in complicated cases might not be as fair.

${ }_{17}$ Van den Heuvel E. Online Dispute Resolution as a solution to cross-border e-disputes. Available at: http://www.oecd.org/internet/consumer/1878940.pdf (accessed: 05.09.2019) 
Cognitive ability and knowledge of a task might be more important than group process when it comes to predicting decision-making effectiveness in complex planning tasks [Devine D., 1999: 630].

\subsection{Ethical, Cultural and Communicative Problems}

Due to cultural differences, solutions reached might not be good in an ethical sense or acceptable to all the parties. As a rule, jurors try to find the right solution, defining the right as that which maximizes the good [Rawls J., 2009: 42]. However, judgments on the right and the good could be made separately. The good can be defined as excellence, pleasure or happiness. The perception of what is ethically good depends on the culture of a certain community. Thus, jury judgments in international online dispute resolution might be not ethically good or fair for the parties in dispute.

Apart from cultural and ethical problems, there are communicative difficulties. The English language, as the main language used in proceedings, substantially affects the result. Not only is it a barrier for disputants from non-English-speaking countries, but it is also a source of cultural differences. There are notable differences for objects that might be familiar to some cultures but not others ${ }^{18}$. In the international dispute resolution process, the people of different nations have different understandings of the same things.

\subsection{Simplification of Procedures and Predetermined Answers}

Dispute resolution platforms adjudicate disputes faster than national courts do. This is achieved, in part, by simplifying procedures and standards. In most cases, the resolution of online disputes involves no investigative procedures, hearing of evidence and testimony or discussion or contest. However, online dispute resolution platforms are poorly suited to complicated problems because simplifying procedures can compromise fairness ${ }^{19}$. In disputes that involve conflicting beliefs about objective truth, the principal criterion of the successful dispute resolution is the accuracy or correctness of decisions resulting from the procedure [Lind A., 1988: 36]. A lack of procedural fairness could result in an unjust settlement of the claim. Simplifying the judicial process increases speed but restricts the ability of jurors to express their thoughts, sometimes limiting their options for answering

${ }^{18}$ Jana R. and Lovejoy J. Exploring and Visualizing an Open Global Dataset. Available at: https://ai.googleblog.com/2017/08/exploring-and-visualizing-open-global.html (accessed: 02.08.2019)

${ }_{19}$ Ambrogi R. Is There a Future for Online Dispute Resolution for Lawyers? Available at: https:// www.lawsitesblog.com/2016/04/future-online-dispute-resolution.html (accessed: 12.09.2019) 
or responding. For example, Kleros limits jurors to the use of Yes/No answers or allows them to input a number or date or to select multiple answers from the available options. When jurors' option are limited, their decisions might be less fair.

\section{Conclusion}

The use of technological dispute resolution has grown considerably over the past decade. This research shows that blockchain dispute resolution is effective for disputes between unidentified persons. The social and psychological aspects of blockchain dispute resolution include such concepts as the wisdom of the crowd and such technological solutions as cryptography. The wisdom of the crowd is the major source of fairness in online dispute resolution. In addition, highly motivated and knowledgeable individuals or small groups of individuals could produce decisions that are more effective, wise and fair - albeit more costly and timeconsuming. Cryptography and distributed ledger technology guarantee the immutability of data. In the absence of other sources, the reputation of jurors and parties is proven by the fact of disputes, the evidence of the case, the fee for the case proceeding and the historical data of a crypto-account.

The fairness of the judgment depends on the number of jurors and their ability to cooperate on the platform. Collusions and manipulation could harm the adjudication process. The balance between cooperative actions for greater fairness and concerted acts of collusion depend on jurors' motivation and moral integrity.

Platforms for blockchain dispute resolution achieve procedural fairness with the help of fewer formalities and by treating the parties involved with dignity and respect. This form of dispute resolution provides a reasonable cost-benefit ratio. It lacks, however, such traditional elements of procedural justice as a neutral forum and jurors with a public reputation for trustworthiness.

At the same time, blockchain dispute resolution meets many objectives of procedural justice. In particular, it supports process-related goals for public involvement, provides inclusive procedures for public participation, enables interactive procedures and ensures a clear justification for decisions.

Drawing on the wisdom of the crowd, blockchain dispute resolution is a reliable instrument for settling differences between the members of an increasingly far-flung global society.

\section{F国 References}

Axelrod R., Hamilton W. (1981) The evolution of cooperation. Science, vol. 211, pp. $1390-1396$. 
Barrett J. (2004) History of alternative dispute resolution: The story of a political, social, and cultural movement. San Francisco: Wiley, p. 320.

Boddington P. (2017) Towards a code of ethics for artificial intelligence. Cham: Springer Verlag, p. 124.

Devine D. (1999) Effects of cognitive ability, task knowledge, information sharing, and conflict on group decision-making effectiveness. Small Group Research, no 30, pp. 608-634.

Habuka H., Rule C. (2017) The Promise and Potential of Online Dispute Resolution in Japan. Available at: https://www.elevenjournals.com/tijdschrift/ijodr/2017/2/ IJODR_2352-5002_2017_004_002_017.pdf (accessed: 21.09.2019)

Hörnle J. (2009) Cross-border internet dispute resolution. Cambridge: Cambridge University Press, p. 286.

Kolb B. (2013) Marketing for Cultural Organizations: New Strategies for Attracting Audiences. N.Y.: Routledge, p.190.

Lawrence R. et al (1997) Procedural justice and public involvement in natural resource decision-making. Society and Natural Resources, no 10, pp. 577-589.

Lee C. (2016). The search for peer firms: When do crowds provide wisdom? Harvard Business School Working Paper, no 15, pp. 14-46.

Lind A. (1988) The social psychology of procedural justice. N.Y.: Springer Science \& Business Media, p. 267.

Lu Z., Xinyu Z. (2017) Study on the Online Dispute Resolution System in China. Advances in Engineering Research, vol. 129, pp. 1-8.

Luppi B. (2013) Jury size and the hung-jury paradox. Journal of Legal Studies, no 42, pp. 399-422.

Mansbridge J. (ed.) (1990) Beyond self-interest. Chicago: Chicago University Press, p. 416.

Raafat R. et al (2009) Herding in humans. Trends in cognitive sciences, vol. 13, pp. 420-428.

Rawls J. (2009) A theory of justice. Cambridge: Harvard University Press, pp. 4, 42.

Schelling T. (1980) The strategy of conflict. Cambridge: Harvard University Press, pp. $57,73,309$.

Sugden R. (1995) A theory of focal points. The Economic Journal, no 105, pp. 533-550.

Surowiecki J. (2004) The wisdom of crowds: Why the many are smarter than the few and how collective wisdom shapes business. In: Economies, Societies and Nations. N.Y.: Doubleday, p. 296.

Tideman N. (2017) Collective decisions and voting: the potential for public choice. Abington-on-Thames: Routledge, p. 360. 
Thibaut J. (1975) Procedural justice: A psychological analysis. N.Y.: Lawrence Erlbaum Inc., p. 160.

Tyler T. (2000) Social justice: Outcome and procedure. International journal of psychology, no 35, pp. 117-125.

Tyler T. (2003) The group engagement model: Procedural justice, social identity, and cooperative behavior. Personality and social psychology review, no 7, pp. 349-361. 